\title{
Purification of native HBHA from Mycobacterium avium subsp. paratuberculosis
}

Louise H Lefrancois' ${ }^{1}$, Christelle C Bodier', Sophie Lecher ${ }^{2,3,4,5}$, Florence B Gilbert', Thierry Cochard', Grégoire Harichaux ${ }^{6,7,8}$, Valérie Labas ${ }^{6,7,8}$, Ana Paula Teixeira-Gomes ${ }^{1,6}$, Dominique Raze ${ }^{2,3,4,5}$, Camille Lochtt, 2,3,5 and Franck Biet ${ }^{*}$

\begin{abstract}
Background: Paratuberculosis remains today a major global problem in animal health, especially for dairy cattle. However, the diagnosis of its etiologic agent, Mycobacterium avium subsp. paratuberculosis (Map), still lacks sensitivity because of the lack of available antigens. Little is known about the virulence factors for this pathogen. In this study we have developed a method to produce and purify the heparin-binding hemagglutinin (HBHA), a major adhesin of Mycobacteria, from a culture of Map.

Findings: For this extremely slow-growing Mycobacterium, a culture was established in a 3-liter bioreactor. Using the bioreactor the amount of the Map biomass was increased 5-fold compared to a classical culture in flasks. The map-HBHA was purified from a Map lysate by heparin-Sepharose chromatography on HiTrap columns. Binding of map-HBHA onto heparin-Sepharose can be reduced in the presence of salt. Consequently, all steps of sample preparation and column equilibration were carried out in $20 \mathrm{mM}$ Tris- $\mathrm{HCl}(\mathrm{pH}$ 7.2). The map-HBHA was eluted by a linear $\mathrm{NaCl}$ gradient. High resolution mass spectrometry analyses revealed that the native form of map-HBHA has posttranslational modifications, including the removal of the initiation methionine, acetylation of the alanine residue at the N-terminal extremity and the presence of methylated lysines in the C-terminal domain of the protein.

Conclusions: An optimized culture of Map in a bioreactor was established to purify the native map-HBHA from a Map lysate by heparin-Sepharose chromatography. The availability of this antigen offers the possibility to study the structure of the protein and to examine its role in pathogenicity, in particular to better understand the specific interactions of Map with the intestinal tissue. The map-HBHA obtained in its native immunogenic form may also be useful to improve the diagnostic test, especially for the development of a new T-cell-based interferon gamma release assays.
\end{abstract}

Keywords: Mycobacterium avium subsp. paratuberculosis, HBHA, heparin-Sepharose chromatography

\section{Findings \\ Background}

Mycobacterium avium subsp. paratuberculosis (Map) is the etiologic agent of a severe granulomatous inflammatory bowel disease in ruminants, known as Johne's disease or paratuberculosis [1,2]. This enzootie remains today a major animal health problem with a high global prevalence causing significant economic losses in the cattle industry [2-6]. One characteristic feature of Map

\footnotetext{
* Correspondence: Franck.Biet@tours.inra.fr

'INRA, UMR ISP 1282 Infectiologie et Santé Publique, Nouzilly F-37380, France Full list of author information is available at the end of the article
}

is its adaptation to the gastrointestinal tract of ruminants. However, the molecular and cellular mechanisms of its interactions with $\mathrm{M}$ cells [7] and epithelial cells [8] are not yet fully elucidated. Mycobacterium-epithelium interactions, much better studied with Mycobacterium tuberculosis, involve an adhesin called heparin-binding hemagglutinin (HBHA), which plays a crucial role in the binding of the mycobacteria to epithelial cells and other non-phagocytic cells $[9,10]$. HBHA is an adhesin that binds sulphated carbohydrates, such as heparin and heparan sulfate, present on the surface of various

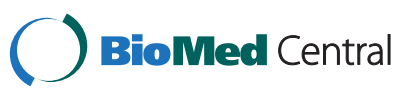


lysine-rich motifs [11]. Native HBHA from $M$. tuberculosis carries methyl groups added post-translationally, which are important for its antigenicity [12]. Several investigations have demonstrated that a HBHA-specific IFN- $\gamma$ response, indicative of latent $M$. tuberculosis infection and protective immunogenicity depends on the methylation of the antigen [13-16].

Comparative genomics suggests that HBHA is also present in Map. In order to study the biochemical characteristics of the HBHA from Map (map-HBHA) and to evaluate its potential in diagnostics and vaccine development, it is essential to have access to native map-HBHA. Our first attempts to purify map-HBHA by heparinSepharose chromatography under conditions used to purify HBHA from $M$. tuberculosis failed to isolate the map-HBHA. In addition, the purification was hampered by the difficulty to obtain sufficient biomass of Map due to the extremely slow growth of this microorganism.

In this study we established a new method of Map culture, using a bioreactor, which substantially increased the biomass yield and shortened the time of culture. In addition, we describe a new purification procedure, which led to the isolation of native map-HBHA.

\section{Results and discussion}

\section{Optimization of Map biomass production in a bioreactor}

Map is one of the slowest-growing Mycobacteria with a mean generation time of 1.38 days [17]. Map cultures thus require long time periods with limited opportunities for recording and correcting parameters. Furthermore, the final product of these cultures was shown to contain high proportions of dead bacilli that may reduce the quality of the proteins harvested [18]. To circumvent these difficulties, we chose to investigate the growth of Map in a bioreactor to increase the biomass, standardize the culture conditions and control potential contaminations. Previous studies using bioreactors have described the standardization of $M$. bovis BCG cultures for vaccine production $[19,20]$. Growth of Map in a bioreactor was compared to conventional culture flasks inoculated in parallel with the same Map pre-culture at an $\mathrm{OD}_{600 \mathrm{~nm}}$ of 0.06. After 40 days, the cultures were centrifuged and the harvested biomasses were weighed. As shown in Figure 1, the biomass harvested from the bioreactor was significantly more important in comparison to the conventional culture in flasks. Using the bioreactor we obtained, as an average of three independent experiments, five times more bacteria than with flask cultures (4 versus $20 \mathrm{~g} \mathrm{~L}^{-1}$ ).

\section{Protein purification}

Our first attempts to purify map-HBHA by heparinSepharose chromatography under conditions used to purify HBHA from $M$. tuberculosis have been unsuccessful.

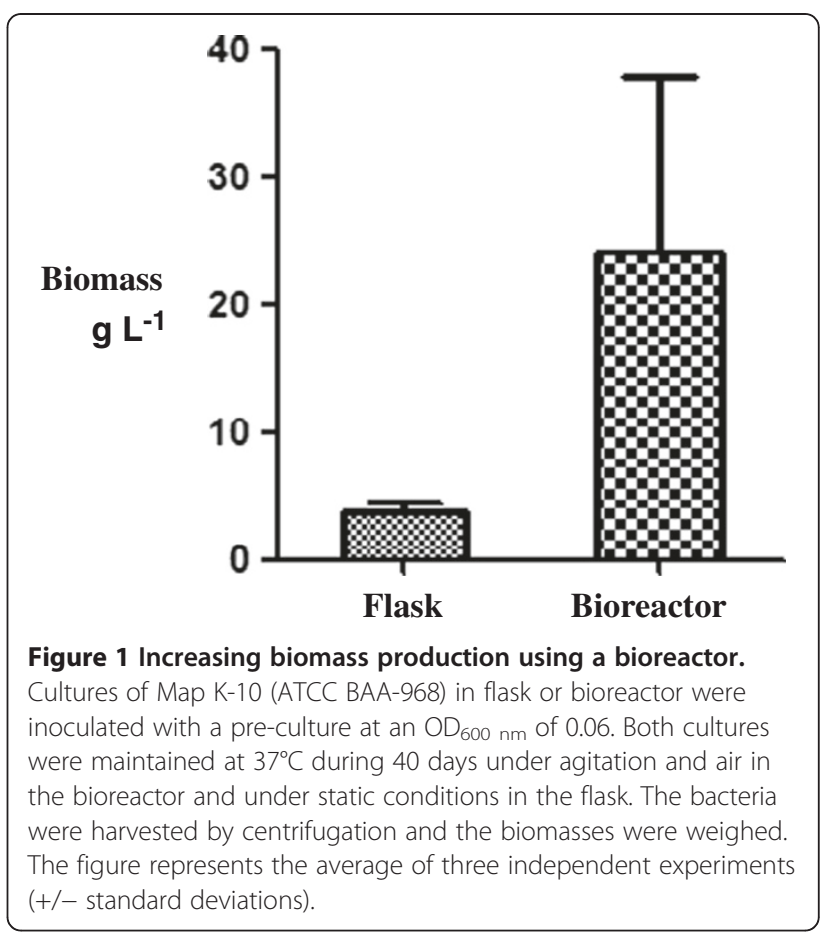

This may be due, at least partly, to the nature of the protein. Although the alignment of the HBHA amino acid sequences from different mycobacterial species indicates that these molecules are highly conserved, the $\mathrm{C}$-terminal lysine-rich domain is rather divergent (Figure 2A). These differences may modify the affinity of the proteins for the heparin-coupled matrix, due to the differences in the distribution of the positively charged lysines involved in the cation- and anion-exchange chromatography (Figure 2B). In a previous study, we have shown that the isolation of the $M$. smegmatis HBHA requires a modification of the elution parameters, as its C-terminal end is less positively charged, compared to that of the M. tuberculosis HBHA [21]. As indicated in Figure 2B, the C-terminal sequence of the map-HBHA contains one acidic residue and 9 positively charged lysines compared to 14 positively charged lysines in HBHA from M. tuberculosis. The predicted isoelectric point (7) is lower than that calculated for HBHA of $M$. tuberculosis (9.6) or M. smegmatis (8.8), suggesting that the binding and elution parameters have to be adjusted. Because of the slow growth of Map, the chromatography conditions were first established with a recombinant form of map-HBHA producing in E. coli.

\section{Heparin-sepharose column}

First, a lysate of recombinant $E$. coli producing mapHBHA was applied onto two types of heparin-Sepharose columns in $0.5 \times$ PBS: the prepacked HiTrap column or heparin-Sepharose CL6B poured into a Pharmacia column. As shown in Figure 3, the recombinant map- 


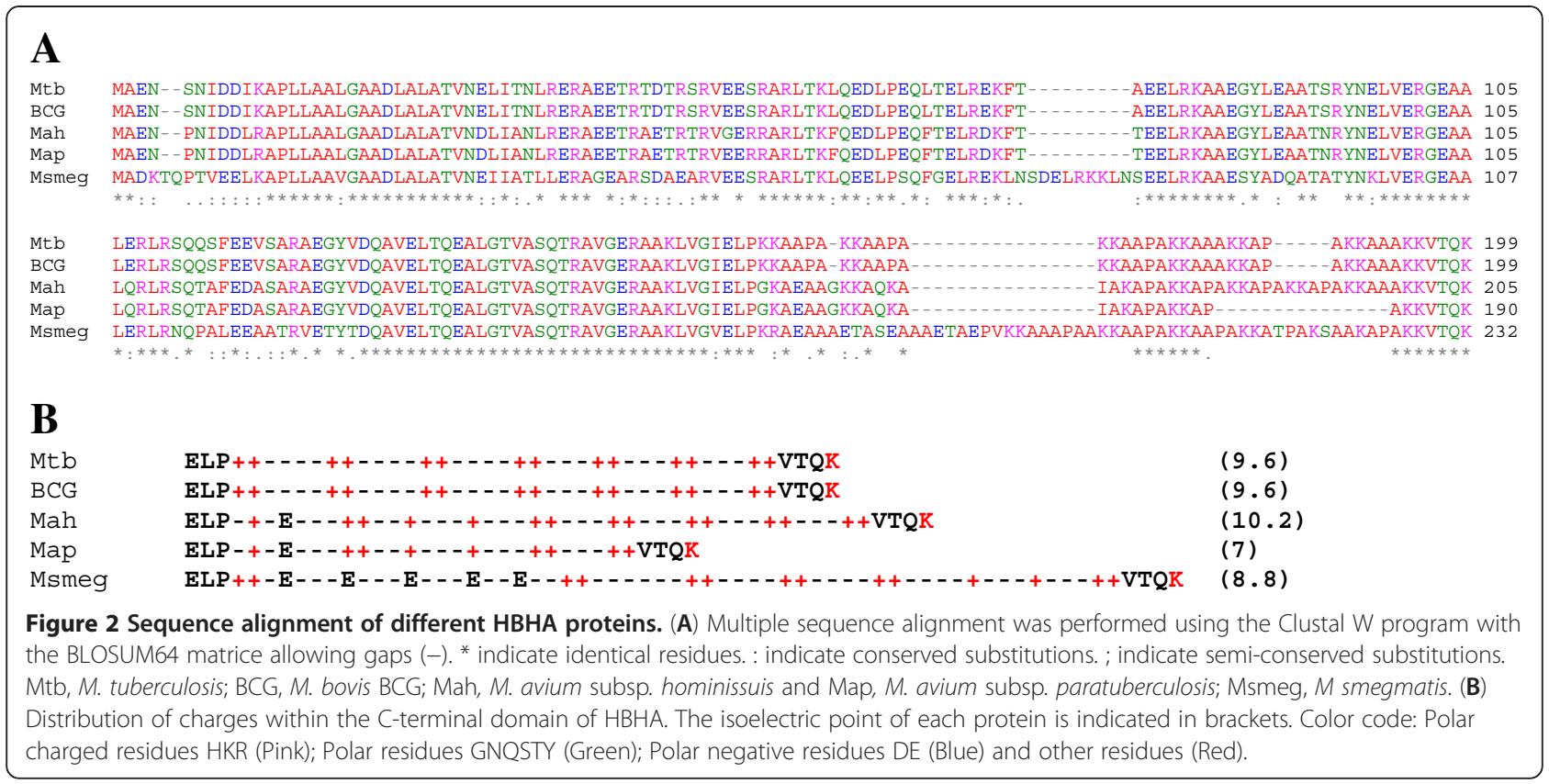

HBHA was successfully purified from a lysate of E. coli. It was eluted from the heparin-Sepharose column at low salt concentrations, starting from $100 \mathrm{mM} \mathrm{NaCl}$. Although both columns showed similar performances with a lysate containing large amounts of recombinant mapHBHA, the HiTrap column, more reproducible in our hands, was preferred.

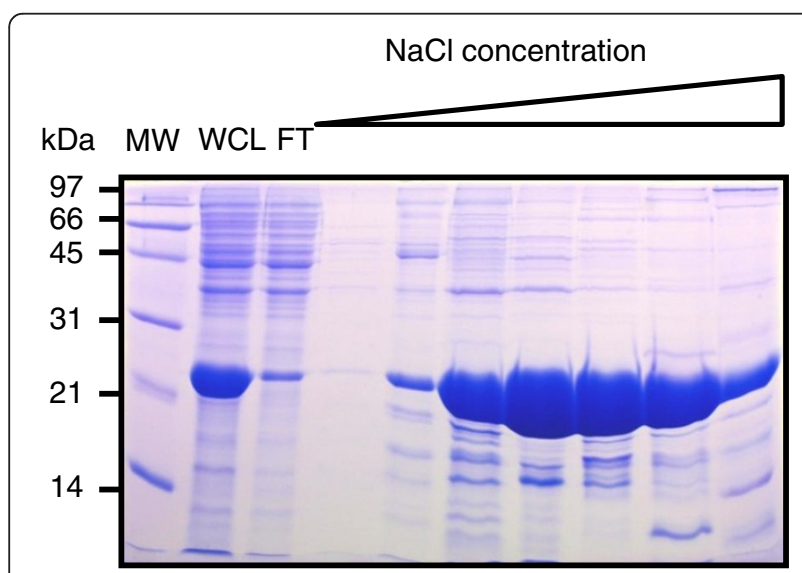

Figure 3 Heparin-Sepharose chromatography of recombinant map-HBHA produced in E. coli. A culture of recombinant $E$. coli producing map-HBHA was sonicated in $0.5 \times$ PBS. The soluble material was loaded onto a heparin-Sepharose HiTrap column and eluted using a 0-1 M NaCl gradient. Whole cell lysate (WCL), flowthrough material (FT) and eluted material were analyzed by SDSPAGE. The fractions eluted between 100 and $350 \mathrm{mM} \mathrm{NaCl}$ contained map-HBHA as determined by HR-MS/MS. The molecular weights (MW) expressed in $\mathrm{kDa}$ are indicated in the left margin.

\section{Buffer conditions}

Surprisingly, when the supernatant of a whole-cell lysate of Map was subjected to purification under the conditions established for recombinant map-HBHA, the native mapHBHA was not isolated. As shown in Figure 4 in late elution fractions only one protein corresponding to $\mathrm{Lbp} / \mathrm{Hlp}$,

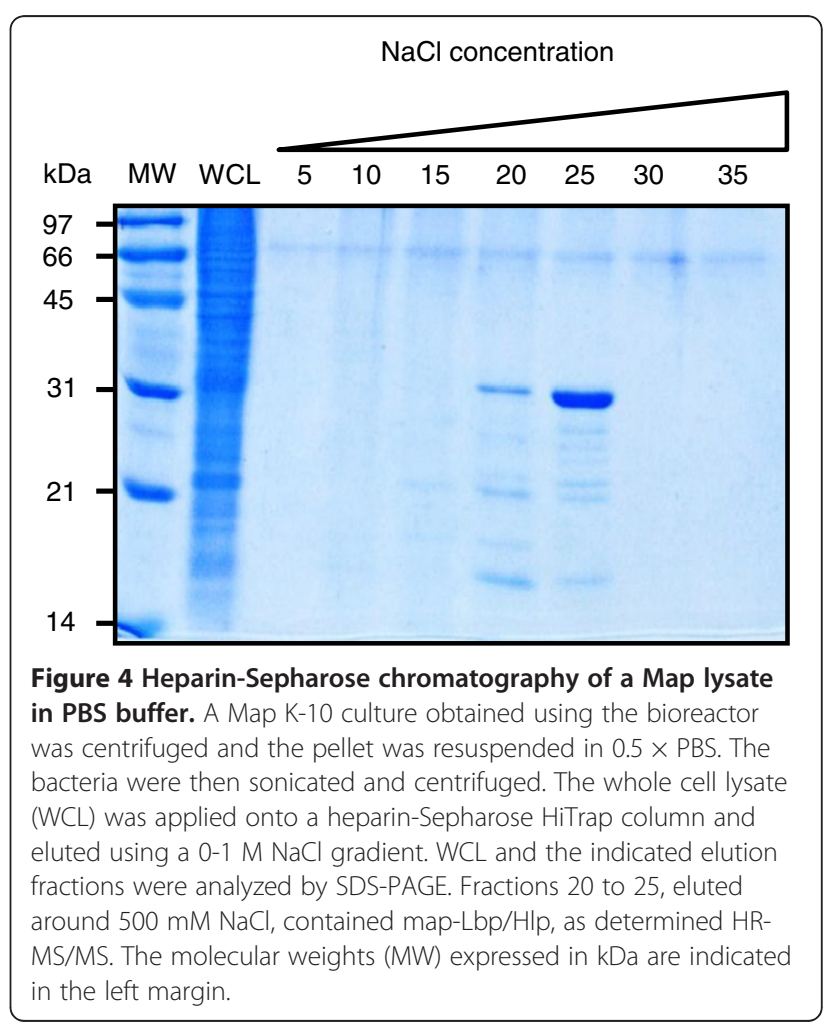


previously described to bind heparin with strong affinity [22], was eluted at $500 \mathrm{mM} \mathrm{NaCl}$ in this study. These results suggest that binding and elution parameters need to be changed to isolate native map-HBHA. The $0.5 \times$ PBS loading buffer was thus replaced by a $20 \mathrm{mM}$ Tris$\mathrm{HCl}$ ( $\mathrm{pH}$ 7.2) buffer to reduce the presence of salt that can inhibit the binding of the protein to the matrix. The mapHBHA prepared in $20 \mathrm{mM}$ Tris- $\mathrm{HCl}(\mathrm{pH} 7.2)$ was able to efficiently bind the heparin-Sepharose matrix and was eluted at approximately $200 \mathrm{mM} \mathrm{NaCl}$ (Figure 5). The early elution of map- $\mathrm{HBHA}$ in the $\mathrm{NaCl}$ gradient suggests a relationship between the number of positive charges in the protein and the binding force to the sulfated sugars. As indicated in Figure 5, Lbp/Hlp eluted later, at $500 \mathrm{mM} \mathrm{NaCl}$.

\section{Mass spectrometry analysis}

To ascertain the identities of the proteins eluted from heparin-Sepharose, High Resolution tandem Mass Spectrometry

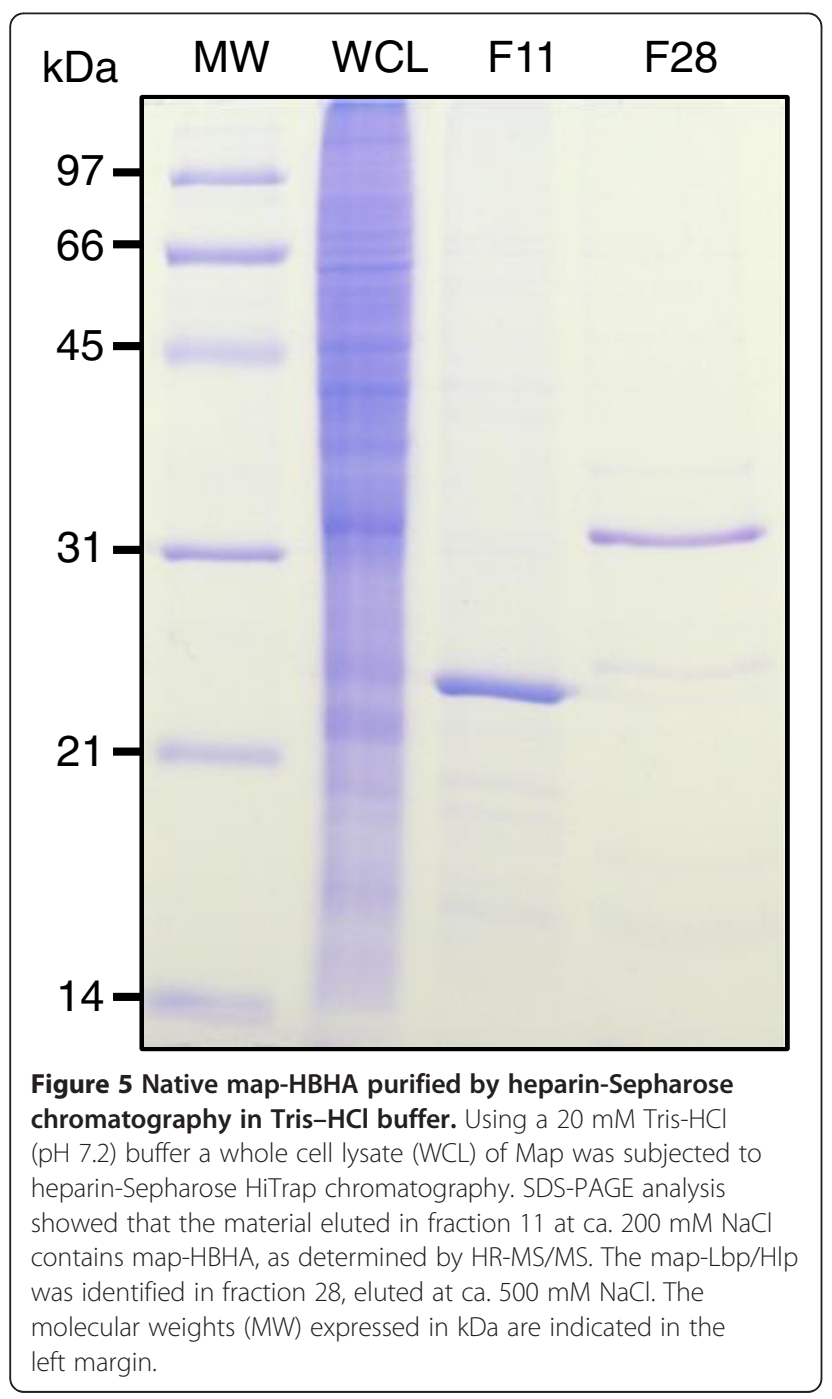

(HR-MS/MS) analyses using a bottom-up approach GeLCMS/MS were carried out. These analyses confirmed that the $25-\mathrm{kDa}$ protein eluted at $200 \mathrm{mM} \mathrm{NaCl}$ corresponds to map-HBHA and that the $31-\mathrm{kDa}$ protein eluted at $500 \mathrm{mM}$ $\mathrm{NaCl}$ corresponds to map-Lbp/Hlp. In addition, HR-MS/ MS also revealed important characteristics of the native proteins purified from the Map culture (Table 1). Similar to the $M$. tuberculosis HBHA [23], native map-HBHA contains no initiation methionine at its $\mathrm{N}$-terminus and that the first amino acid is thus an alanine residue. The cleavage of the initiation methionine is a post-translational common process in Mycobacteria [24,25]. The HR-MS/MS analyses also indicated that the amino-terminal alanine is acetylated. This post-translational modification already reported for other mycobacterial proteins may be an important regulator of protein functions [26,27].

Another feature of native map-HBHA, revealed by HR-MS/MS, is the presence of methylated amino acids as indicated in Figure 6 and Table 1. Among the peptides analyzed in this study, the lysine residues 154 and 168 were mono-methylated. Other proteomic analyses are necessary to determine the complete methylation profile of the HBHA produced by Map. Although the exact role of the methylation remains to be elucidated, this post-translational modification was shown to be crucial for the immunogenicity of the $M$. tuberculosis HBHA. Only the native, methylated protein is able to induce strong IFN- $\gamma$ secretion by peripheral blood mononuclear cells from latently infected human [14] and when administered in combination with strong Th1promoting adjuvants only the methylated form was able to confer protection against $M$. tuberculosis in mouse models [16].

Altogether these data highlight the importance of having access to proteins in their native form with their specific post-translational modifications to understand their function, their location and to envisage their use as antigens for diagnostics or vaccine development.

\section{Conclusions}

The objective of this study was to develop the conditions that allow us to purify native HBHA from a lysate of Map. To obtain sufficient biomass of Map, for which the culture is slow and tedious, a bioreactor culture method was developed. Under these conditions it was possible to obtain a biomass of $20 \mathrm{~g}$ per liter of culture, a 5-fold higher yield than in traditional culture conditions. Native map-HBHA was purified by heparin-Sepharose chromatography. HiTrap columns gave the best and most reproducible results. Due to the specific chemical characteristics of native map-HBHA, in particular the charges present in the C-terminal part of the protein, the Map lysate had to be prepared in $20 \mathrm{mM}$ Tris- $\mathrm{HCl}$ ( $\mathrm{pH}$ 7.2) to allow for optimal binding of map-HBHA to the heparin-Sepharose matrix. 
Table 1 Identification of map-HBHA by mass spectrometry analysis

\begin{tabular}{|c|c|c|}
\hline Peptides identified by HR-MS/MS & Peptide position start - end & Peptide modification \\
\hline${ }^{2} A_{a c} E N P N I D D L R{ }^{11}$ & $2-11$ & Acetylated \\
\hline${ }^{60}$ FQEDLPEQFTELR ${ }^{72}$ & $60-72$ & \\
\hline${ }^{73}$ DKFTTEELR ${ }^{81}$ & $73-81$ & \\
\hline${ }^{82}$ KAAEGYLEAATNR ${ }^{94}$ & $82-94$ & \\
\hline${ }^{83}$ AAEGYLEAATNR ${ }^{94}$ & $83-94$ & \\
\hline${ }^{109}$ LRSQTAFEDASAR $^{121}$ & $109-121$ & \\
\hline${ }^{111}$ SQTAFEDASAR ${ }^{121}$ & $111-121$ & \\
\hline${ }^{111}$ SQTAFEDASARAEGYVDQAVELTQEALGTVASQTR ${ }^{145}$ & $111-145$ & \\
\hline${ }^{122}$ AEGYVDQAVELTQEALGTVASQTR ${ }^{145}$ & $122-145$ & \\
\hline${ }^{151} \mathrm{AAK}_{\mathrm{me}} \mathrm{LVGIELPGK}^{162}$ & $151-162$ & Methylated \\
\hline${ }^{154}$ LVGIELPGK $^{162}$ & $154-162$ & \\
\hline${ }^{154}$ LVGIELPGKAEAAGK ${ }_{\text {me }}^{168}$ & $154-168$ & Methylated \\
\hline${ }^{154}{ }^{\text {LVGIELPGKAEAAGKK }}{ }^{169}$ & 154-169 & \\
\hline Peptides highlighted onto sequence ${ }^{a}$ & & \\
\hline
\end{tabular}

HR-MS/MS analyses revealed post-translational modifications, such as presence of an acetyl alanine residue at the $\mathrm{N}$-terminus and methyl-lysines in the C-terminal part of the protein. In this study, we have thus optimized the Map culture conditions and the purification of native mapHBHA, which is therefore now available for structurefunction studies and investigations for use in diagnosis or vaccine development against Map.

\section{Methods}

Bacterial strains, growth conditions and DNA manipulations Mycobacterium avium subsp. paratuberculosis (Map) strain K-10 (ATCC BAA-968) was grown at $37^{\circ} \mathrm{C}$ in Sauton medium supplemented with $2 \mathrm{mg} \mathrm{L}^{-1}$ of mycobactin J (IDVET, Montpellier, France). E. coli TOP10 (Invitrogen Carsbad, CA) and E. coli BL21(DE3) (Novagen, Darmstadt, DE) were grown in LB medium supplemented with $50 \mu \mathrm{g} \mathrm{mL}{ }^{-1}$ kanamycin as appropriate. Restriction enzymes, T4 DNA ligase and other molecular biology reagents were purchased from New England Biolabs, Roche or Promega. PCRs were performed using a Bio-Rad thermal cycler model iCycler and the PCR products were sequenced by GenomExpress (Grenoble, France).

\section{Cultivation of Map K-10 in bioreactor}

A Map K-10 pre-culture was prepared in Sauton medium to obtain an initial optical density at $600 \mathrm{~nm}$ of 0.06 . This was then inoculated either in $175 \mathrm{~cm}^{2}$-Greiner Bio-one Flasks maintained at $37^{\circ} \mathrm{C}$ in static conditions or in a 3liter bioreactor (Setric Génie Industriel, Toulouse, France) constantly kept at $37^{\circ} \mathrm{C}$ with a stirring rate at $110 \mathrm{rpm}$ and
$12 \mathrm{~L} \mathrm{~h}^{-1}$ of air. During growth, serial time samplings were performed to determine absorbance at $600 \mathrm{~nm}$. Once the stationary phase was reached, the bacteria were harvested by centrifugation at $7,000 \times g$ for $15 \mathrm{~min}$ at $4^{\circ} \mathrm{C}$ and stored at $-20^{\circ} \mathrm{C}$ until use.

Protein purification by heparin-Sepharose chromatography A frozen Map pellet corresponding to $5 \mathrm{~g}$ was thawed, washed twice with $0.5 \times$ PBS or $20 \mathrm{mM}$ Tris $-\mathrm{HCl}$ $(\mathrm{pH} 7.2)$ and heated at $80^{\circ} \mathrm{C}$ during $30 \mathrm{~min}$. Heat-killed bacteria were centrifuged at $10,000 \times g$ for $20 \mathrm{~min}$. The Map pellet was resuspended in $45 \mathrm{~mL} 0.5 \times$ PBS or 20 $\mathrm{mM}$ Tris- $\mathrm{HCl}(\mathrm{pH} 7.2)$ and sonicated intermittently in a Kimble HS N45500-30 tube using a Branson Sonifier $250 \mathrm{D}$ for $20 \mathrm{~min}$ repeated 4 times, on ice. The soluble material obtained after centrifugation at $13,000 \times g$ for $20 \mathrm{~min}$ at $4^{\circ} \mathrm{C}$ was filtered at $0.45 \mu$ and applied onto the heparin-Sepharose matrix.

All chromatographic steps were carried out on the Biologic chromatography system (BioRad), at room temperature and the absorbance at $280 \mathrm{~nm}$ was continuously monitored during the purification. Two types of columns were investigated. One protocol used the HiTrap Heparin HP (1 mL, GE Healthcare) column $(0.7 \times 2.5 \mathrm{~cm})$ prepacked with heparinSepharose. In the second protocol $1 \mathrm{~g}$ of heparin Sepharose CL-6B (GE Healthcare) resuspended in $5 \mathrm{~mL}$ of $0.5 \times$ PBS or $20 \mathrm{mM}$ Tris $-\mathrm{HCl}$ (pH 7.2) was poured into a $1.5 \times 10 \mathrm{~cm}$ column (Pharmacia), according to the recommendations of the supplier. The columns were washed with $100 \mathrm{~mL}$ of $0.5 \times$ PBS or 
$20 \mathrm{mM}$ Tris- $\mathrm{HCl}(\mathrm{pH}$ 7.2) until the absorbance at $280 \mathrm{~nm}$ was close to 0 . The bound material was eluted by a $0-1 \mathrm{M} \mathrm{NaCl}$ linear gradient using a flow rate maintained at $0.6 \mathrm{~mL} \mathrm{~min}^{-1}$ and automatically collected in $1 \mathrm{~mL}$ fractions. Whole cell lysates, flowthrough material and eluted fractions were analyzed by $12 \%$ sodium dodecyl sulfate-polyacrylamide gel electrophoresis (SDS-PAGE) performed according to Laemmli [28].

\section{Cloning, sequencing and production of recombinant map- $H B H A$ in $E$. coli}

The map-HBHA-encoding gene (MAP3968) was amplified by PCR from chromosomal DNA using the Taq DNA polymerase (Promega) and two synthetic oligonucleotides (Sigma) with the following sequences: $5^{\prime}$ - TAT ACATATGACCATGGCGGAAAACCCGAACATCG -3' and $5^{\prime}$ - ATATAAGCTTGGTACCCACGAGGTGGTTC ACGCC -3 , containing NdeI and HindIII sites (underlined). The fragment was amplified after a short denaturation cycle of $3 \mathrm{~min}$ at $95^{\circ} \mathrm{C}$ by using 35 cycles as follows: $95^{\circ} \mathrm{C}$ for $30 \mathrm{~s}, 57^{\circ} \mathrm{C}$ for $30 \mathrm{~s}$, and $72^{\circ} \mathrm{C}$ for $30 \mathrm{~s}$ with a final elongation cycle at $72^{\circ} \mathrm{C}$ for $10 \mathrm{~min}$. The PCR product containing the map-HBHA-coding sequence was digested by NdeI and HindIII and then inserted into pET$24 \mathrm{a}(+)$ (Novagen), generating pET::map-HBHA. This plasmid was used to transform E. coli TOP 10 for sequencing and $E$. coli BL21(DE3) for protein expression. After transformation, E. coli BL21(DE3) cells were grown at $37^{\circ} \mathrm{C}$ in $250 \mathrm{~mL} \mathrm{LB}$ broth supplemented with $50 \mu \mathrm{g} \mathrm{mL}^{-1}$ kanamycin. At an $\mathrm{OD}_{600}$ of 0.5 , IPTG was added to a final concentration of $1 \mathrm{mM}$, and growth was continued for $4 \mathrm{~h}$. The culture was then centrifuged at $7,000 \times g$ for $15 \mathrm{~min}$ at $4^{\circ} \mathrm{C}$. The pellet obtained was stored at $-20^{\circ} \mathrm{C}$ until applied onto heparin Sepharose as described above.

The GenBank accession numbers for the mapHBHA (strains K-10 and ATCC19698) sequences are 
[mapK10_HBHA JX536266 and map19698_HBHA JX536267].

\section{Identification of the purified Map proteins by high resolution mass spectrometry analysis}

Proteins were digested in-gel with trypsin as previously described [29]. Peptides were analyzed by nanoLC-MS/ MS using an Ultimate ${ }^{\circledR} 3000$ RSLC coupled to a LTQ Velos Orbitrap Mass Spectrometer. Samples were loaded onto a trap column (Acclaim PepMap $100 \mathrm{C}_{18}, 100 \mu \mathrm{m}$ inner diameter $\times 2 \mathrm{~cm}$ ) at a flow rate of at $5 \mu \mathrm{L} \mathrm{min}{ }^{-1}$ with $4 \%$ solvent B $(0.1 \%$ formic acid, $15.9 \%$ water, $84 \%$ acetonitrile) and $96 \%$ solvent A (0.1\% formic acid, $97.9 \%$ water, $2 \%$ acetonitrile). Peptides were fractionated using a nano-column (Acclaim PepMap $\mathrm{C}_{18}, 75 \mu \mathrm{m}$ inner diameter $\times 15 \mathrm{~cm}$ ), with a nanoflow rate of $300 \mathrm{nl} \mathrm{min}{ }^{-1}$ by applying a gradient of 4-55\% B for $60 \mathrm{~min}$. The LTQ Velos Orbitrap instrument was operated in a datadependent mode with $R=30,000$. In the scan range of $\mathrm{m} / \mathrm{z} 300-1800$, the 10 most intense peptide ions with charge states $\geq 2$ were isolated for HCD fragmentation. Raw data files were converted to MGF. The data were searched against nr NCBI database (Eubacteria) using MASCOT search engine (version 2.3). Carbamidomethylcysteine was set as a fixed modification, and oxidation of methionine, N-terminal acetylation and methylation of lysine were set as variable modifications. Two missed cleavages were allowed. The tolerance of the ions was set to $10 \mathrm{ppm}$ for parent and $0.1 \mathrm{Da}$ for fragment ion matches. Mascot results were subjected to the Scaffold 3 software (version 3.2). Peptide identifications were accepted if they could be established at a greater than $95.0 \%$ probability as specified by the Peptide Prophet algorithm [30]. Protein identifications were accepted if they could be established at a greater than 99.0\% probability and contained at least two identified peptides [31]. Identified post-translational modifications were validated using Scaffold PTM (version 2.0). Localization sites were accepted if they could be established at a greater than $99 \%$ probability as specified by the Ascore algorithm [32].

\section{Competing interests}

The authors have no competing interests.

\section{Authors' contributions}

FB, LL and DR conceived of the study, participated in its design and coordination, collated and analyzed the data. $F B, L L, D R$ and $C L$ drafted the manuscript. CB, SL, TC, LL, FG, APTG, GH and VL participated in the laboratory and field work. All authors read, criticized and approved the final manuscript.

\section{Acknowledgements}

FB, LL, CB, TC, FG and APTG were supported by the Institut National de la Recherche Agronomique (INRA).

The high resolution mass spectrometer was financed (SMHART project) by the European Regional Development Fund (ERDF), the Conseil Régional du
Centre, the French National Institute for Agricultural Research (INRA) and the French National Institute of Health and Medical Research.

\section{Author details}

${ }^{1}$ INRA, UMR ISP 1282 Infectiologie et Santé Publique, Nouzilly F-37380, France. ${ }^{2}$ CNRS UMR, Lille 8204, France. ${ }^{3}$ INSERM, Lille U1019, France. ${ }^{4}$ Institut Pasteur de Lille, Lille, France. ${ }^{5}$ Univ Lille Nord de France, Lille F-59000, France. ${ }^{6}$ INRA, UMR85 Physiologie de la Reproduction et des Comportements Plateforme d'Analyse Intégrative des Biomarqueurs, Nouzilly, France. ${ }^{7}$ CNRS, UMR, Nouzilly 7247, France. ${ }^{8}$ IFCE, Nouzilly F-37380, France.

Received: 11 October 2012 Accepted: 30 January 2013

Published: 7 February 2013

\section{References}

1. Clarke CJ: The pathology and pathogenesis of paratuberculosis in ruminants and other species. J Comp Pathol 1997, 116(3):217-261.

2. Harris NB, Barletta RG: Mycobacterium avium subsp. Paratuberculosis in veterinary medicine. Clin Microbiol Rev 2001, 14(3):489-512.

3. Nielsen SS, Toft N: A review of prevalences of paratuberculosis in farmed animals in europe. Prev Vet Med 2009, 88(1):1-14.

4. Ott SL, Wells SJ, Wagner BA: Herd-level economic losses associated with Johne's disease on US dairy operations. Prev Vet Med 1999, 40(3-4):179-192

5. Smith RL, Grohn YT, Pradhan AK, Whitlock RH, Van Kessel JS, Smith JM, Wolfgang DR, Schukken YH: A longitudinal study on the impact of Johne's disease status on milk production in individual cows. J Dairy Sci 2009, 92(6):2653-2661.

6. Wilson DJ, Rood K, Biswas P, Byrem TM: Herd-level prevalence of Johne's disease in utah and adjacent areas of the intermountain west as detected by a bulk-tank milk surveillance project. J Dairy Sci 2010, 93(12):5792-5797.

7. Momotani E, Whipple DL, Thiermann AB, Cheville NF: Role of M cells and macrophages in the entrance of mycobacterium paratuberculosis into domes of ileal Peyer's patches in calves. Vet Pathol 1988, 25(2):131-137.

8. Pott J, Basler T, Duerr CU, Rohde M, Goethe R, Hornef MW: Internalizationdependent recognition of mycobacterium avium ssp. Paratuberculosis by intestinal epithelial cells. Cell Microbiol 2009, 11(12):1802-1815.

9. Menozzi FD, Bischoff R, Fort E, Brennan MJ, Locht C: Molecular characterization of the mycobacterial heparin-binding hemagglutinin, a mycobacterial adhesin. Proc Natl Acad Sci U S A 1998, 95(21):12625-12630.

10. Pethe K, Alonso S, Biet F, Delogu G, Brennan MJ, Locht C, Menozzi FD: The heparin-binding haemagglutinin of $\mathrm{M}$. Tuberculosis Is required for extrapulmonary dissemination. Nature 2001, 412(6843):190-194.

11. Pethe K, Aumercier M, Fort E, Gatot C, Locht C, Menozzi FD: Characterization of the heparin-binding site of the mycobacterial heparin-binding hemagglutinin adhesin. J Biol Chem 2000, 275(19):14273-14280.

12. Pethe K, Bifani $P$, Drobecq $H$, Sergheraert C, Debrie AS, Locht C, Menozzi FD: Mycobacterial heparin-binding hemagglutinin and laminin-binding protein share antigenic methyllysines that confer resistance to proteolysis. Proc Natl Acad Sci U S A 2002, 99(16):10759-10764.

13. Masungi C, Temmerman S, Van Vooren JP, Drowart A, Pethe K, Menozzi FD, Locht C, Mascart F: Differential T and B cell responses against mycobacterium tuberculosis heparin-binding hemagglutinin adhesin in infected healthy individuals and patients with tuberculosis. J Infect Dis 2002, 185(4):513-520.

14. Temmerman S, Pethe K, Parra M, Alonso S, Rouanet C, Pickett T, Drowart A, Debrie AS, Delogu G, Menozzi FD, et al: Methylation-dependent T cell immunity to mycobacterium tuberculosis heparin-binding hemagglutinin. Nat Med 2004, 10(9):935-941.

15. Guerrero GG, Locht C: Recombinant HBHA boosting effect on BCGinduced immunity against mycobacterium tuberculosis infection. Clin Dev Immunol 2011, 2011:730702.

16. Parra M, Pickett T, Delogu G, Dheenadhayalan V, Debrie AS, Locht C, Brennan MJ: The mycobacterial heparin-binding hemagglutinin is a protective antigen in the mouse aerosol challenge model of tuberculosis. Infect Immun 2004, 72(12):6799-6805.

17. Lambrecht RS, Carriere JF, Collins MT: A model for analyzing growth kinetics of a slowly growing mycobacterium sp. Appl Environ Microbiol 1988, 54(4):910-916. 
18. Milstien JB, Gibson JJ: Quality control of BCG vaccine by WHO: a review of factors that may influence vaccine effectiveness and safety. Bull World Health Organ 1990, 68(1):93-108.

19. Dietrich G, Mollenkopf HJ, Weber H, Knapp B, Diehl KD, Hess J, Blackkolb F, Broker M, Kaufmann SH, Hundt E: Cultivation of mycobacterium bovis BCG in bioreactors. J Biotechnol 2002, 96(3):259-270.

20. Nyabenda J, Bautens E, Borremans M, Verhofstadt R, Weckx M, Marchal A: The production of mycobacterial antigens by homogeneous culture in a fermentor. J Biol Stand 1988, 16(4):259-267.

21. Biet $F$, Angela de Melo Marques M, Grayon M, Xavier da Silveira EK, Brennan PJ, Drobecq H, Raze D, Vidal Pessolani MC, Locht C, Menozzi FD: Mycobacterium smegmatis produces an HBHA homologue which is not involved in epithelial adherence. Microbes Infect 2007, 9(2):175-182.

22. Lefrancois LH, Pujol C, Bodier CC, Teixeira-Gomez AP, Drobecq H, Rosso ML, Raze D, Dias AA, Hugot JP, Chacon O, et al: Characterization of the mycobacterium avium subsp. Paratuberculosis laminin-binding/histonelike protein (Lbp/Hlp) which reacts with sera from patients with Crohn's disease. Microbes Infect 2011, 13(6):585-594.

23. Menozzi FD, Rouse JH, Alavi M, Laude-Sharp M, Muller J, Bischoff R, Brennan $\mathrm{MJ}$, Locht C: Identification of a heparin-binding hemagglutinin present in mycobacteria. J Exp Med 1996, 184(3):993-1001.

24. Kanudia P, Mittal M, Kumaran S, Chakraborti PK: Amino-terminal extension present in the methionine aminopeptidase type 1c of mycobacterium tuberculosis is indispensible for its activity. BMC Biochem 2011, 12:35.

25. Zhang X, Chen S, Hu Z, Zhang L, Wang H: Expression and characterization of two functional methionine aminopeptidases from mycobacterium tuberculosis H37Rv. Curr Microbiol 2009, 59(5):520-525.

26. Hwang CS, Shemorry A, Varshavsky A: N-terminal acetylation of cellular proteins creates specific degradation signals. Science 2010, 327(5968):973-977.

27. Okkels LM, Muller EC, Schmid M, Rosenkrands I, Kaufmann SH, Andersen P, Jungblut PR: CFP10 Discriminates between nonacetylated and acetylated ESAT-6 of mycobacterium tuberculosis by differential interaction. Proteomics 2004, 4(10):2954-2960

28. Laemmli UK: Cleavage of structural proteins during the assembly of the head of bacteriophage T4. Nature 1970, 227(259):680-685.

29. Bourin M, Gautron J, Berges M, Attucci S, Le Blay G, Labas V, Nys Y, RehaultGodbert S: Antimicrobial potential of egg yolk ovoinhibitor, a multidomain kazal-like inhibitor of chicken egg. J Agric Food Chem 2011, 59(23):12368-12374

30. Keller A, Nesvizhskii Al, Kolker E, Aebersold R: Empirical statistical model to estimate the accuracy of peptide identifications made by MS/MS and database search. Anal Chem 2002, 74(20):5383-5392.

31. Nesvizhskii Al, Keller A, Kolker E, Aebersold R: A statistical model for identifying proteins by tandem mass spectrometry. Anal Chem 2003, 75(17):4646-4658.

32. Beausoleil SA, Villen J, Gerber SA, Rush J, Gygi SP: A probability-based approach for high-throughput protein phosphorylation analysis and site localization. Nat Biotechnol 2006, 24(10):1285-1292.

doi:10.1186/1756-0500-6-55

Cite this article as: Lefrancois et al:: Purification of native HBHA from Mycobacterium avium subsp. paratuberculosis. BMC Research Notes 2013 6:55.

\section{Submit your next manuscript to BioMed Central and take full advantage of:}

- Convenient online submission

- Thorough peer review

- No space constraints or color figure charges

- Immediate publication on acceptance

- Inclusion in PubMed, CAS, Scopus and Google Scholar

- Research which is freely available for redistribution 